\title{
LXI. On the rate of oxidation of phosphorus, sulphur, and aldehyde
}

\section{Thomas Ewan B.Sc. Ph.D.}

To cite this article: Thomas Ewan B.Sc. Ph.D. (1894) LXI. On the rate of oxidation of phosphorus, sulphur, and aldehyde, Philosophical Magazine Series 5, 38:235, 505-536, DOI: 10.1080/14786449408620668

To link to this article: http://dx.doi.org/10.1080/14786449408620668

曲 Published online: 08 May 2009.

Submit your article to this journal $[\pi$

Џ Article views: 2

Q View related articles $₫$ 
IJONDON, EDINBURGH, AND DUBLIN

\title{
PHILOSOPHICAL MAGAZINE
}

\author{
AND \\ JOURNAL OF SCIENCE.
}

[FIFTH SERIES.]

$D E C E M B E R 1894$.

LXI. On the Rate of Oxidation of Phosphorus, Sulphur, and Aldehyde. By Thомas Ewan, B.Se., Ph.D., late 1851 Exhibition Scholar in Chemistry at the Owens College*.

\section{INTRODUCTION.}

A CCORDING to our present knowledge the velocity with A which a chemical change takes place is dependent on the concentrations of the substances taking part in the change, and the connexion between the two is of such a nature that a greater concentration corresponds to a greater velocity.

Under these circumstances it is of great interest that in a number of instances oxygen gas appears to act chemically more vigorously, that is with greater velocity, when it is dilute than when it is more concentrated.

The first mention of this behaviour, so far as I know, was

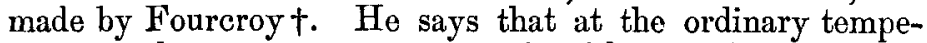
rature and pressure pure oxygen is without action on phosphorus, although ordinary air acts vigorously. In 1798 van Marum $\ddagger$ found that a piece of phosphorus glowed much more brightly in rarefied than in ordinary air, and that it even took fire at very low pressures if surrounded by a little cotton-wool. These observations were confirmed and extended by subsequent observers.

* Communicated by the Author.

† Memoires de l'Académie des Sciences, 1788. (1798).

Verhandelingen uitgegeeven door Teyler's Tweede Genootschap, 10

Phil. Mag. S. 5. Vol. 38. No. 235. Dec. 1894. $2 \mathrm{M}$ 
According to Thorpe and Tutton* phosphorous oxide, $\mathrm{P}_{4} \mathrm{O}_{6}$, shows phenomena in presence of oxygen gas which possess the strongest resemblance to those exhibited by phosphorus itself. They suggest that the more rapid reaction at lower pressures is due to the increased volatility of the phosphorous oxide.

Joubert $\dagger$ noticed similar behaviour with sulphur and arsenic.

Friedel and Ladenburg $\ddagger$ found that a mixture of silicon hydride, $\mathrm{SiH}_{4}$, and oxygen inflames spontaneously on decreasing its pressure, and Houton do Labillardière $\$$ had previously made a similar observation with phosphine $\left(\mathrm{PH}_{3}\right)$.

Van de Stadt \| mentions that nickel carbonyl, Ni(CO), appears also to behave similarly. Reicher and Jorissen Tी found, however, that it is still spontaneously inflammable in oxygen under a pressure of 13 atmospheres.

Engelmann ** found that certain Bacteria show a preference for a certain definite concentration of dissolved oxygen. Greater or smaller concentrations seem to be less favourable to their existence.

Labillardière's observation with phosphine was repeated by van't Hoff $\dagger+$, who found that at ordinary remperatures the spontaneons inflammation of the mixture took place when the partial pressure of the oxygen was about $\frac{1}{10}$ atmosphere. The gases were preserved over a saturated solution of calcium chloride. When the partial pressure of the oxygen was higher or lower than $\frac{1}{10}$ atmosphere, only a slow combination took place.

H. J. van de Stadt $\ddagger \ddagger$ in 1893 investigated the subject more fully in order to find how the velocity of the slow combustion which precedes the explosion changes with the concentration. He found that the reaction proceeded slowly and with a nearly constant velocity, which showed no noticeable acceleration until the explosion-pressure was reached, when the explosion took place, sometimes at once, sometimes on standing.

This reaction was therefore not a very suitable one for the

* Journ. Chem. Soc. 1890 , p. 569.

† Thèses présentées à la Faculté des Sciences de Paris, 1874.

† Ann. Ch. Phys. [4] xxiii. p. 430 (1871).

\$ Ann. Ch. Phys. vi. p. 304 (1817).

II Zeit. Phys. Chem. 1893, xii. p. 322.

I Maandblad voor Natuurwetenschappen, No. 1 (1894).

** Botanische Zeitung, 1882, p. 320 .

t† Etudes de Dynamique Chimique, p. 60 (1884).

tf Zeit. Phys. Chem. 1893, xii. p. 322. 
study of the connexion between the velocity of the change and the concentration of the oxygen. For this reason, and at the suggestion of Professor van't Hoff, I took up the study of the velocity of the reaction between phosphorus and oxygen.

\section{Rate of Oxidation of Phosphorus in Moist Oxygen.}

(a) Behaviour in Air.

Some measurements have already been recorded by Ikeda*. $\mathrm{He}$ found that at $19^{\circ}$ the oxidation of phosphorus in moist air takes place with a velocity which is nearly proportional to the concentration of the oxygen. At the lower pressures the reaction went a little faster than is required by exact proportionality.

My first experiments were made in the same way as those of Ikeda. The apparatus consisted of a bottle of $1 \frac{1}{2}$ to 2 litres capacity with two necks, into one of which a test-tube was fitted by means of a cork, while the other communicated with a manometer. The test-tube reached to about the middle of the bottle, and its lower, closed, end was surrounded by a cylinder of phosphorus which was kept cool by a current of water, of the same temperature as the water-bath, which flowed through the test-tube. The whole apparatus stood in a large water-bath the temperature of which was kept constant. The experiments were made as follows :-The bottle, containing a little water and air, was placed in the thermostat, connected with the manometer, and allowed to stand until it had assumed the temperature of the bath. The phosphorus cylinder was then quickly placed in position and the pressure read off. Subsequent readings of the pressure made at convenient intervals furnished the data from which the velocity of the reaction was calculated. The concentration of the oxygen is proportional to its partial pressure so long as the volume remains constant (which was the case in the method just described), and the decrease of pressure per minute is proportional to the quantity of oxygen which undergoes change per minute-that is, to the velocity of the reaction.

The phosphorus was so little acted on during an experiment that its surface remained practically undiminished.

The numbers obtained in two experiments made in this way are given in the following Table (I.). They agree with those obtained by Ikeda in showing that the velocity of the reaction (in moist air) diminishes a little more slowly than the partial pressure of the oxygen. This is seen in the increase in the values of $K^{\prime}$ (column 4). These numbers are

* Journ. Coll. Science, Imperial University, Japan, vi. p. 43 (1893). 
calculated on the assumption that the rate of the reaction is proportional to the partial pressure of the oxygen. Or

$$
-\frac{d p}{d t}=\mathrm{K}^{\prime} p
$$

On integration this becomes

$$
-\log p=\mathrm{K}^{\prime} t+\text { const. }
$$

We have $p=p_{0}$, when $t=0, p_{0}$ being the pressure of the oxygen at the beginning of the experiment.

We have, therefore,

and

$$
\text { const. }=-\log p_{0}
$$

$$
\mathrm{K}^{\prime}=\frac{1}{t} \log \frac{p_{0}}{p} \text {. . . . . . }
$$

\begin{tabular}{|c|c|c|c|c|}
\hline \multicolumn{5}{|c|}{$\begin{aligned} \text { Pressure of aqueous vapour } . & =17.8 \text { millim. } \\
,, \quad \text { phosphorus-vapour } & =0.113,\end{aligned}$} \\
\hline $\begin{array}{c}\text { Time, in } \\
\text { minutes, } \\
\text { from the } \\
\text { beginning. } \\
t .\end{array}$ & $\begin{array}{l}\text { Total } \\
\text { pressure. } \\
\text { P. }\end{array}$ & $\begin{array}{l}\text { Partial } \\
\text { pressure of } \\
\text { Oxygen } \\
=p\end{array}$ & $\mathbf{K}^{\prime}$. & K. \\
\hline $\begin{array}{r}0 \\
25 \\
50 \\
75 \\
100 \\
130\end{array}$ & $\begin{array}{l}773 \cdot 1 \\
750 \cdot 6 \\
729 \cdot 7 \\
714 \cdot 3 \\
697 \cdot 4 \\
682 \cdot 2\end{array}$ & $\begin{array}{r}1578 \\
135.3 \\
114.0 \\
99.0 \\
82.1 \\
66.9\end{array}$ & $\begin{array}{l}.00267 \\
.00282 \\
.00271 \\
\cdot 00284 \\
.00286\end{array}$ & $\begin{array}{l}42 \cdot 0 \\
43 \cdot 1 \\
40^{-1} \\
42 \cdot 3 \\
42 \cdot 1\end{array}$ \\
\hline Pres & $\begin{array}{l}\text { Tempera } \\
\text { e of aqu } \\
\text { pho }\end{array}$ & $\begin{array}{l}\text { e }=20^{\circ} 5 \\
\text { us vapour } \\
\text { lorus-vapo }\end{array}$ & $\begin{array}{r}20^{\circ} \cdot 68 . \\
=17.9 \\
=0.11\end{array}$ & lim. \\
\hline $\begin{array}{r}0 \\
25 \\
50 \\
70 \\
100 \\
130 \\
171 \\
201 \\
246\end{array}$ & $\begin{array}{l}764 \cdot 6 \\
749 \cdot 5 \\
732 \cdot 9 \\
723 \cdot 2 \\
707 \cdot 1 \\
693 \cdot 5 \\
677 \cdot 4 \\
667 \cdot 4 \\
653 \cdot 2\end{array}$ & $\begin{array}{r}156 \cdot 0 \\
1409 \\
124.3 \\
1146 \\
98 \cdot 5 \\
84.9 \\
68 \cdot 8 \\
58 \cdot 8 \\
446\end{array}$ & $\begin{array}{l}\cdot 00177 \\
.00197 \\
.00191 \\
000200 \\
000203 \\
000208 \\
\cdot 00211 \\
000221\end{array}$ & $\begin{array}{l}27 \cdot 2 \\
28 \cdot 3 \\
29 \cdot 0 \\
29 \cdot 8 \\
800 \\
30 \cdot 3 \\
30 \cdot 4 \\
31 \cdot 4\end{array}$ \\
\hline
\end{tabular}

TABLE I.-Phosphorus and Moist Air.

The vapour-pressure of phosphorus was determined by Joubert, loe, cit. 


\section{Influence of the Rate of Evaporation.}

The fact that $K^{\prime}$ increases as the pressure falls shows that the reaction takes place somewhat faster at lower pressures than one would expect if its velocity were directly proportional to the pressure. This may be due to the fact that substances evaporate more rapidly into a gaseous atmosphere when its pressure is small than when it is larger. There can be little doubt that the reaction takes place between phosphorus-vapour and oxygen; and, furthermore, if it is allowable to take the phosphorescent light as an indication of the locality of the reaction, it takes place close to the surface of the phosphorus so long as the pressure of the oxygen is not very small*. There are thus grounds for supposing that the phosphorus-vapour is oxidized as fast as it is evolved from the surface of the phosphorus, and therefore that the velocity with which the reaction goes forward will be directly proportional to the rate of evaporation of the phosphorus. By making this assumption, as we shall see, it is at any rate possible to give a coherent and fairly satisfactory account of reactions the courses of which would otherwise appear to be totally exceptional.

According to Stefant, when all the other conditions remain constant, the rate of evaporation of a liquid into a gas is connected with the pressure of the latter by the following formula :-

where

$$
v=c \log \frac{\mathrm{P}}{\mathrm{P}-p^{\prime}}
$$

$v=$ the rate of evaporation,

$\mathrm{P}=$ total pressure of the gas and vapour,

and $\quad c=$ some constant.

$p^{\prime}=$ the vapour-pressure of the liquid,

Introducing this correction for the changeable velocity of evaporation into equation (1), we obtain

$$
-\frac{d p}{d t}=\mathrm{K} p \cdot \log \frac{\mathrm{P}}{\mathrm{P}-p}, \ldots . . .
$$

In order to in tegrate this equation we may write $p=\mathrm{P}-a$, where $a$ is the partial pressure of the nitrogen and aqueous vapour in the mixture of gases, and therefore constant. After making this substitution and expanding the logarithm,

* The luminous phenomena accompanying the oxidation of phosphorus have been carefully described by v. Marum, loc. cit.; Joubert, Thises, 1874; Fischer, J. prakt. Chem. xxxv. p. 343 (1845); Schrötter, Sitzungsber. Wien. Akad. ix. p. 414 (1852), and others.

† Sitzungsber. K. Akad. d.Wiss. Wien, lxvii. 1878, p. 385. 
the equation may be brought into the form

$$
-\mathrm{K} d t=\frac{d \mathrm{P}}{\mathrm{P}-a}\left[\frac{\mathrm{P}}{p^{\prime}}-\frac{1}{2}-\frac{1}{12} \frac{p^{\prime}}{\mathrm{P}}-\frac{1\left(p^{\prime}\right)^{2}}{24 \mathrm{P}^{2}}-\& \mathrm{c} .\right] .
$$

This can be easily integrated between the limits $P_{0}$ and $P$, and gives :-

$$
\begin{aligned}
\mathrm{K} t=\frac{\mathrm{P}_{0}-\mathrm{P}}{p^{\prime}} & +\left(\log \frac{\mathrm{P}_{0}-a}{\mathrm{P}-a}\right)\left[\frac{a}{p^{\prime}}-\frac{1}{2}-\frac{p^{\prime}}{12 a}-\frac{p^{2}}{24 a^{2}}-\& c .\right] \\
& +\left(\log \frac{\mathrm{P}_{0}}{\mathrm{P}}\right)\left[\frac{p^{\prime}}{12 a}+\frac{p^{\prime 2}}{24 a^{2}}+\& \mathrm{c} .\right] \\
& +\frac{p^{\prime 2}}{24 a} \cdot \frac{\mathrm{P}_{0}-\mathrm{P}}{\mathrm{P}_{0} \mathrm{P}} \& \mathrm{c} . \text {. . . . . . . . }
\end{aligned}
$$

For phosphorus at ordinary temperatures, $p^{\prime}$ is so small compared with $a$ that the equation may, without appreciable error, be written

$$
\mathrm{K} t=\frac{\mathrm{P}_{0}-\mathrm{P}}{p^{\prime}}+\left(\log \frac{\mathrm{P}_{0}-a}{\mathrm{P}-a}\right)\left[\frac{a}{p^{\prime}}-\frac{1}{2}\right] . .
$$

The values of $K$ in the fifth column of Table $I$. have been calculated by means of this equation. The numbers are more nearly constant than those obtained by means of the uncorrected equation (1).

It appears, therefore, from these experiments that the velocity of the reaction is proportional to the pressure of the oxygen. This cannot be true at all pressures, however, for when the pressure of the oxygen is greater than a certain limit the velocity of the reaction becomes zero.

\section{(b) Phosphorus in Moist Oxygen. Behaviour at Higher Pressures.}

A further series of measurements was therefore made in which the whole range of pressures at which the reaction takes place was studied.

For this purpose a somewhat different form of apparatus was used. After various trials that shown in fig. 1 was found to be most convenient. The glass vessel E P A (50-70 cubic centim. capacity) was conected by means of a capillary tube ( $\frac{1}{2}$ millim. diameter) with the tap $\mathrm{B}$ and with the manometer $D$. The joint at $C$ was usually made by means of a ground-glass joint luted with mercury; occasionally a thick indiarubber tube was used. The manometer was arranged so that the mercury always stood at the same height in the limb $\mathrm{D}$, the volume of the apparatus therefore remained constant. A mercury-gange was mostly used, but some of the experiments at lower pressures were made with a manometer 
in which the mercury was replaced by bromnaphthalene. This allowed of a more accurate reading of the pressure, and the vapour of the bromnaphthalene did not appear to interfere in any way with the course of the reaction. The phosphorus was purified by molting it under a ailute solution of potassium bichromate and sulphuric acid, and carefully washing it.

Fig. 1.

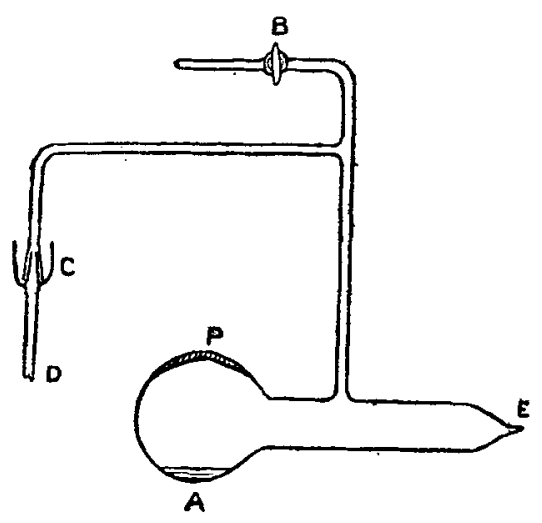

A piece of this phosphorus was brought into the apparatus through $\mathrm{E}$, melted at $\mathrm{P}$, distributed in as thin a layer as possible over the upper surface of the bulb, and allowed to solidify in that position. This was generally done in an atmosphere of carbon dioxide, sometimes in vacuo. By this means as large a surface of the phosphorus as possible is exposed to the cooling action of the water in the bath in which the apparatus is plunged. The product of the oxidation also tends to fall and not to collect on the surface of the phosphorus. A little water was placed in the apparatus at A, and $\mathrm{E}$ sealed up before the blowpipe.

After placing the apparatus in position in the water-bath, it was evacuated as completely as possible and oxygen allowed to enter. This operation was repeated several times. A precaution which is of importance is to keep the phosphorus cold; otherwise, on allowing the oxygen to flow into the vacuous apparatus, it is very apt to take fire. This is especially the case when the oxygen is dry and the pressure is very low ; with oxygen which had been dried by passing over phosphorous pentoxide I have even seen the spontaneous inflammation occur at $0^{\circ} \mathrm{C}$. The pressure was probably less than that due to 1 millim. of mercury. 
No attempt was made to measure the absolute velocity of the reaction, as this would have involved the accurate measurement of the area of the surface of the phosphorus. The constants obtained are therefore different in each experiment, The temperature varied irregularly between the limits given.

TABLE II.-Phosphorus and Oxygen. (Saturated with aqueous vapour.)

\begin{tabular}{|c|c|c|c|c|c|}
\hline \multicolumn{6}{|c|}{ 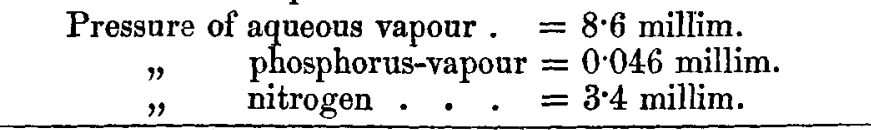 } \\
\hline $\begin{array}{l}\text { Time in minutes } \\
\text { from beginning } \\
=t .\end{array}$ & \multicolumn{2}{|c|}{$\begin{array}{l}\text { Total pressure in } \\
\text { mm. of mercury. } \\
\mathbf{P} \text {. }\end{array}$} & \multicolumn{2}{|c|}{$\begin{array}{c}\text { Partial pressure } \\
\text { of Oxygen. } \\
p .\end{array}$} & $\begin{array}{l}\text { K. } \\
\text { Calculated from } \\
\text { equation } 2 b .\end{array}$ \\
\hline $\begin{array}{c}0 \\
83 \\
96 \\
124 \cdot 5 \\
152 \\
169 \\
195 \\
236\end{array}$ & \multicolumn{2}{|c|}{$\begin{array}{l}94 \cdot 3 \\
43 \cdot 7 \\
38 \cdot 4 \\
27 \cdot 1 \\
21 \cdot 2 \\
18 \cdot 0 \\
14 \cdot 7 \\
13 \cdot 1\end{array}$} & \multicolumn{2}{|r|}{$\begin{array}{r}82 \cdot 3 \\
31 \cdot 7 \\
26 \cdot 4 \\
15 \cdot 1 \\
9 \cdot 2 \\
6 \cdot 0 \\
2 \cdot 7 \\
1 \cdot 1\end{array}$} & $\begin{array}{l}16 \cdot 2 \\
15 \cdot 7 \\
15 \cdot 3 \\
14 \cdot 2 \\
13 \cdot 9 \\
13 \cdot 4 \\
12 \cdot 2\end{array}$ \\
\hline \multicolumn{6}{|c|}{$\begin{array}{c}\text { Pressure of aqueous vapour }=17.6 \text { to } 18.2 \text { millim. } \\
, \quad \text { phosphorus-vapour }=0.116 \text { millim. }\end{array}$} \\
\hline$t$. & P. & $\begin{array}{l}\text { Press } \\
\text { Nitr }\end{array}$ & $\begin{array}{l}\text { ogen. } \\
\text { ogen of }\end{array}$ & $p$ & $\mathbf{K}$. \\
\hline $\begin{array}{r}0 \\
22 \\
50 \\
80 \\
171\end{array}$ & $\begin{array}{l}750 \cdot 7 \\
750 \cdot 7 \\
749 \cdot 6 \\
745 \cdot 8 \\
736 \cdot 5\end{array}$ & & ", & $\begin{array}{l}695 \cdot 6 \\
695 \cdot 6 \\
694 \cdot 5 \\
690 \cdot 7 \\
681 \cdot 3\end{array}$ & $\begin{array}{l}0 \cdot 0 \\
0 \cdot 06 \\
0 \cdot 18 \\
0 \cdot 77\end{array}$ \\
\hline $\begin{array}{r}0 \\
255\end{array}$ & $\begin{array}{l}736.5 \\
671 \cdot 0\end{array}$ & & ", & $\begin{array}{l}680 \cdot 6 \\
615 \cdot 3\end{array}$ & $2 \cdot 39$ \\
\hline $\begin{array}{r}0 \\
57\end{array}$ & $\begin{array}{l}601 \cdot 6 \\
542 \cdot 7\end{array}$ & & $\begin{array}{l}3 \cdot 4 \\
"\end{array}$ & $\begin{array}{l}\mathbf{5 4 9 . 9} \\
491.0\end{array}$ & $9 \cdot 79$ \\
\hline $\begin{array}{r}0 \\
30\end{array}$ & $\begin{array}{l}487 \cdot 7 \\
457 \cdot 2\end{array}$ & & $\begin{array}{l}0 \cdot 1 \\
"\end{array}$ & $\begin{array}{l}439 \cdot 4 \\
408 \cdot 9\end{array}$ & 9.86 \\
\hline $\begin{array}{r}0 \\
\mathbf{2 5}\end{array}$ & $\begin{array}{l}397 \cdot 8 \\
372 \cdot 3\end{array}$ & & $\begin{array}{l}6.2 \\
" y\end{array}$ & $\begin{array}{l}353 \cdot 4 \\
327.9\end{array}$ & 9.95 \\
\hline
\end{tabular}


of Phosphorus, Sulphur, and Aldehyde.

TABLe II.-Phosphorus and Oxygen (continued).

\begin{tabular}{|c|c|c|c|}
\hline \multicolumn{4}{|c|}{$\begin{array}{l}\text { Temperature }=20^{\circ} .43 \text { to } 20^{\circ} .64 \\
\text { are of aqueous vapour } .=17.9 \text { millim. } \\
\text { phosphorus-vapour }=0.116 \text { millim. }\end{array}$} \\
\hline$t$. & P. & $p$ & $\mathbf{K}$. \\
\hline $\begin{array}{r}0 \\
79\end{array}$ & $\begin{array}{l}801 \cdot 8 \\
801 \cdot 8\end{array}$ & $\begin{array}{l}7839 \\
7839\end{array}$ & \\
\hline $\begin{array}{r}0 \\
52\end{array}$ & $\begin{array}{l}740 \cdot 7 \\
741 \cdot 9\end{array}$ & $\begin{array}{l}7228 \\
7240\end{array}$ & \\
\hline $\begin{array}{r}0 \\
43\end{array}$ & $\begin{array}{l}689 \cdot 0 \\
684 \cdot 2\end{array}$ & $\begin{array}{l}671 \cdot 1 \\
666 \cdot 3\end{array}$ & 0.99 \\
\hline $\begin{array}{c}0 \\
37.5\end{array}$ & $\begin{array}{l}6159 \\
581.8\end{array}$ & $\begin{array}{l}598 \cdot 0 \\
563 \cdot 9\end{array}$ & $8 \cdot 08$ \\
\hline $\begin{array}{r}0 \\
24\end{array}$ & $\begin{array}{l}491 \cdot 5 \\
463 \cdot 3\end{array}$ & $\begin{array}{l}473 \cdot 6 \\
445 \cdot 4\end{array}$ & $10 \cdot 52$ \\
\hline $\begin{array}{c}0 \\
225\end{array}$ & $\begin{array}{l}340 \cdot 2 \\
312 \cdot 2\end{array}$ & $\begin{array}{l}322 \cdot 3 \\
294 \cdot 3\end{array}$ & 1134 \\
\hline \multicolumn{4}{|c|}{$\begin{array}{l}\text { Temperature }=20^{\circ} \cdot 18 \text { to } 20^{\circ} \cdot 24 \\
\text { ef aqueous vapour } .=17 \cdot 6 \text { millim. } \\
\text { phosphorus-vapour }=0.111 \text { millim. }\end{array}$} \\
\hline$t$. & P. & $p$ & K. \\
\hline $\begin{array}{r}0 \\
17\end{array}$ & $\begin{array}{l}484 \cdot 1 \\
420 \cdot 8\end{array}$ & $\begin{array}{l}457 \cdot 4 \\
394 \cdot 1\end{array}$ & $35 \cdot 6$ \\
\hline$\underset{36 \cdot 5}{0}$ & $\begin{array}{l}252 \cdot 5 \\
146.7\end{array}$ & $\begin{array}{l}225 \cdot 8 \\
120 \cdot 0\end{array}$ & 302 \\
\hline $\begin{array}{r}0 \\
15 \\
40 \\
60\end{array}$ & $\begin{array}{r}107 \cdot 7 \\
65 \cdot 7 \\
32 \cdot 3 \\
26 \cdot 7\end{array}$ & $\begin{array}{r}81 \cdot 0 \\
39 \cdot 0 \\
5 \cdot 6 \\
0 \cdot 0\end{array}$ & $\begin{array}{l}36 \cdot 4 \\
26 \cdot 3 \\
26 \cdot 6\end{array}$ \\
\hline \multicolumn{4}{|c|}{$\begin{array}{l}\text { Temperature }=20^{\circ} \cdot 54 \text { to } 20^{\circ} \cdot 6 . \\
\text { of aqueous vapour }=18.0 \text { millim. } \\
\text { phosphorus-vapour }=0.116 \text { millim. } \\
\text { nitrogen . . }=6.6 \text { millim. }\end{array}$} \\
\hline$t$. & P. & $p$ & K. \\
\hline $\begin{array}{r}0 \\
21 \\
40 \\
50 \\
64 \\
84 \\
104 \\
124\end{array}$ & $\begin{array}{r}264 \cdot 0 \\
200 \cdot 2 \\
150 \cdot 5 \\
124 \cdot 0 \\
90 \cdot 0 \\
50 \cdot 0 \\
30 \cdot 8 \\
25 \cdot 3\end{array}$ & $\begin{array}{r}239.4 \\
175.6 \\
1259 \\
99.4 \\
65.4 \\
25.4 \\
6.2 \\
0.7\end{array}$ & $\begin{array}{l}29 \cdot 3 \\
27 \cdot 9 \\
27 \cdot 9 \\
27 \cdot 8 \\
27 \cdot 8 \\
27 \cdot 0 \\
26 \cdot 8\end{array}$ \\
\hline
\end{tabular}


TaBLe II.-Phosphorus and Oxygen (continued). Temperature $=29^{\circ} \cdot 59$ to $29^{\circ} \cdot 79$.

Pressure of aqueous vapour . $=31$ millim.

$" \quad$ phosphorus-vapour $=0.25$ millim.

" nitrogen . . . = 8 millim.

\begin{tabular}{|c|c|c|c}
\hline$t$. & P. & $p$. & K. \\
\hline 0 & $230 \cdot 0$ & $191 \cdot 0$ & \\
$4 \cdot 5$ & $204 \cdot 4$ & $165 \cdot 4$ & $27 \cdot 7$ \\
$9 \cdot 5$ & $170 \cdot 0$ & $131 \cdot 0$ & $31 \cdot 4$ \\
$14 \cdot 5$ & $138 \cdot 9$ & $99 \cdot 7$ & $32 \cdot 0$ \\
$19 \cdot 5$ & $114 \cdot 4$ & $75 \cdot 2$ & $31 \cdot 1$ \\
$24 \cdot 5$ & $91 \cdot 3$ & $52 \cdot 3$ & $30 \cdot 9$ \\
$30 \cdot 5$ & $73 \cdot 7$ & $34 \cdot 7$ & $29 \cdot 1$ \\
$34 \cdot 5$ & $65 \cdot 6$ & $26 \cdot 6$ & $28 \cdot 0$ \\
$39 \cdot 5$ & $57 \cdot 5$ & $18 \cdot 3$ & $26 \cdot 6$ \\
$45 \cdot 5$ & $52 \cdot 7$ & $13 \cdot 5$ & $24 \cdot 6$ \\
$49 \cdot 0$ & $50 \cdot 2$ & $11 \cdot 0$ & $23 \cdot 6$ \\
$54 \cdot 0$ & $47 \cdot 3$ & $8 \cdot 0$ & $22 \cdot 6$ \\
\hline
\end{tabular}

Temperature $=29^{\circ} \cdot 15$ to $29^{\circ} \cdot 3$.

Pressure of aqueous vapour . $=30.1 \mathrm{~mm}$. mercury.

" phosphorus-vapour $=0.205 \mathrm{~mm}$. "

" nitrogen . . = $3.02 \mathrm{~mm}$. ,

Bromnaphthalene manometer used. Sp. gr. of the bromnaphthalene was 1.5108 at ordinary temperature.

\begin{tabular}{|c|c|c|c|}
\hline$t$. & $\begin{array}{l}\mathbf{P} \text { in mm. of } \\
\text { bromnapthalene. }\end{array}$ & $\begin{array}{c}p \text { in mm. of } \\
\text { mercury. }\end{array}$ & $\mathbf{K}$. \\
\hline $\begin{array}{l}0 \\
5 \\
13 \\
17 \\
23 \\
29 \cdot 5 \\
37 \\
47 \\
56 \\
93\end{array}$ & $\begin{array}{r}1210 \cdot 0 \\
954 \cdot 5 \\
626 \cdot 5 \\
521 \cdot 0 \\
444 \cdot 5 \\
391 \cdot 0 \\
357 \cdot 0 \\
316 \cdot 5 \\
300 \cdot 5 \\
300 \cdot 0\end{array}$ & $\begin{array}{r}101 \cdot 0 \\
72 \cdot 6 \\
33 \cdot 9 \\
24 \cdot 5 \\
15 \cdot 9 \\
10 \cdot 0 \\
6.2 \\
1.7 \\
0.1 \\
0\end{array}$ & $\begin{array}{l}39 \cdot 1 \\
38 \cdot 3 \\
35 \cdot 6 \\
23 \cdot 5 \\
22 \cdot 0 \\
19 \cdot 3 \\
19 \cdot 9 \\
21 \cdot 3\end{array}$ \\
\hline $\begin{array}{c}\text { Pressure } \\
" \\
\text { "2 } \\
\text { Bromne }\end{array}$ & $\begin{array}{l}\text { Temperature = } \\
\text { leous vapour } \\
\text { sphorus-vapou } \\
\text { rogen } \\
\text { lene manometer us }\end{array}$ & $\begin{aligned} & 9^{\circ} .6 \text { to } 29^{\circ} \\
= & 281 \mathrm{~mm} . \mathrm{b} \\
= & 2.43 \mathrm{~mm} . \\
= & 52.2 \mathrm{~mm} .\end{aligned}$ & $\begin{array}{l}\text { phthe } \\
\text { " } \\
\text { " }\end{array}$ \\
\hline$t$. & $\begin{array}{c}\mathbf{P} \text { in mm. of } \\
\text { bromnaphthalene. }\end{array}$ & $\begin{array}{c}p \text { in mm. of } \\
\text { mercury. }\end{array}$ & $\mathbf{K}$ \\
\hline $\begin{array}{r}0 \\
4 \cdot 5 \\
8 \cdot 5 \\
12 \cdot 5 \\
18 \cdot 5 \\
27 \cdot 0 \\
46 \cdot 0 \\
106.0\end{array}$ & $\begin{array}{r}1375 \cdot 0 \\
1212 \cdot 5 \\
1049 \cdot 5 \\
887 \cdot 0 \\
684 \cdot 0 \\
597 \cdot 0 \\
532 \cdot 5 \\
476 \cdot 5\end{array}$ & $\begin{array}{r}115 \cdot 7 \\
97 \cdot 7 \\
79 \cdot 6 \\
61 \cdot 5 \\
38 \cdot 9 \\
29 \cdot 3 \\
22 \cdot 1 \\
15 \cdot 9\end{array}$ & $\begin{array}{r}20 \cdot 0 \\
21 \cdot 8 \\
22 \cdot 9 \\
23 \cdot 4 \\
18 \cdot 8 \\
12 \cdot 4 \\
6 \cdot 0\end{array}$ \\
\hline
\end{tabular}


of Phosphorus, Sulphur, and Aldehyde.

TABLE II.-Phosphorus and Oxygen (continued).

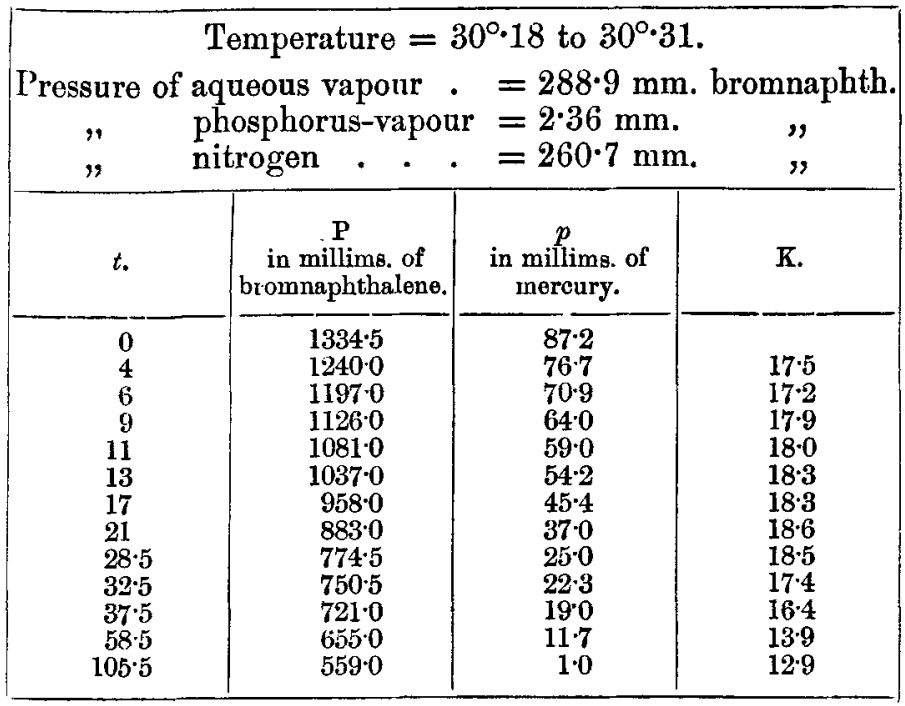

Determinations of the limiting pressure, above which no reaction takes place, were only made at $20^{\circ}$. In one experiment at $20^{\circ} .2$ (see Table II.) the reaction just began when the pressure of the oxygen was 696 millim. In another at $20^{\circ} .5$ it began at 671 millim., but not at 723 millim. We may therefore say that at a temperature of $20^{\circ}-21^{\circ}$ phosphorus will just begin to oxidize in wet oxygen when its pressure is about 700 millim.

Joubert* gives two series of experiments on the pressure at which phosphorus just begins to be luminous in oxygen. At $20^{\circ} \cdot 2$, one series gave 787 millim., the other 666 millim. The pressure at which oxidation just begins appears, therefore, to be identical with that at which the phosphorescence just becomes visible.

The curves in fig. 2 show the connexion between the pressure and the velocity of the reaction between phosphorus and wet oxygen. The experiments at $20^{\circ}$ being the most complete have been used in drawing them. The values of the velocities of reaction have been obtained by dividing the successive decrements of the pressure by the corresponding increments of the time.

These values of $\frac{\Delta p}{\Delta t}$ are taken as ordinates, and the mean

* Loc. cit. 
values of the partial pressure of oxygen in each interval as abscissæ. The actual numbers, which are easily calculated

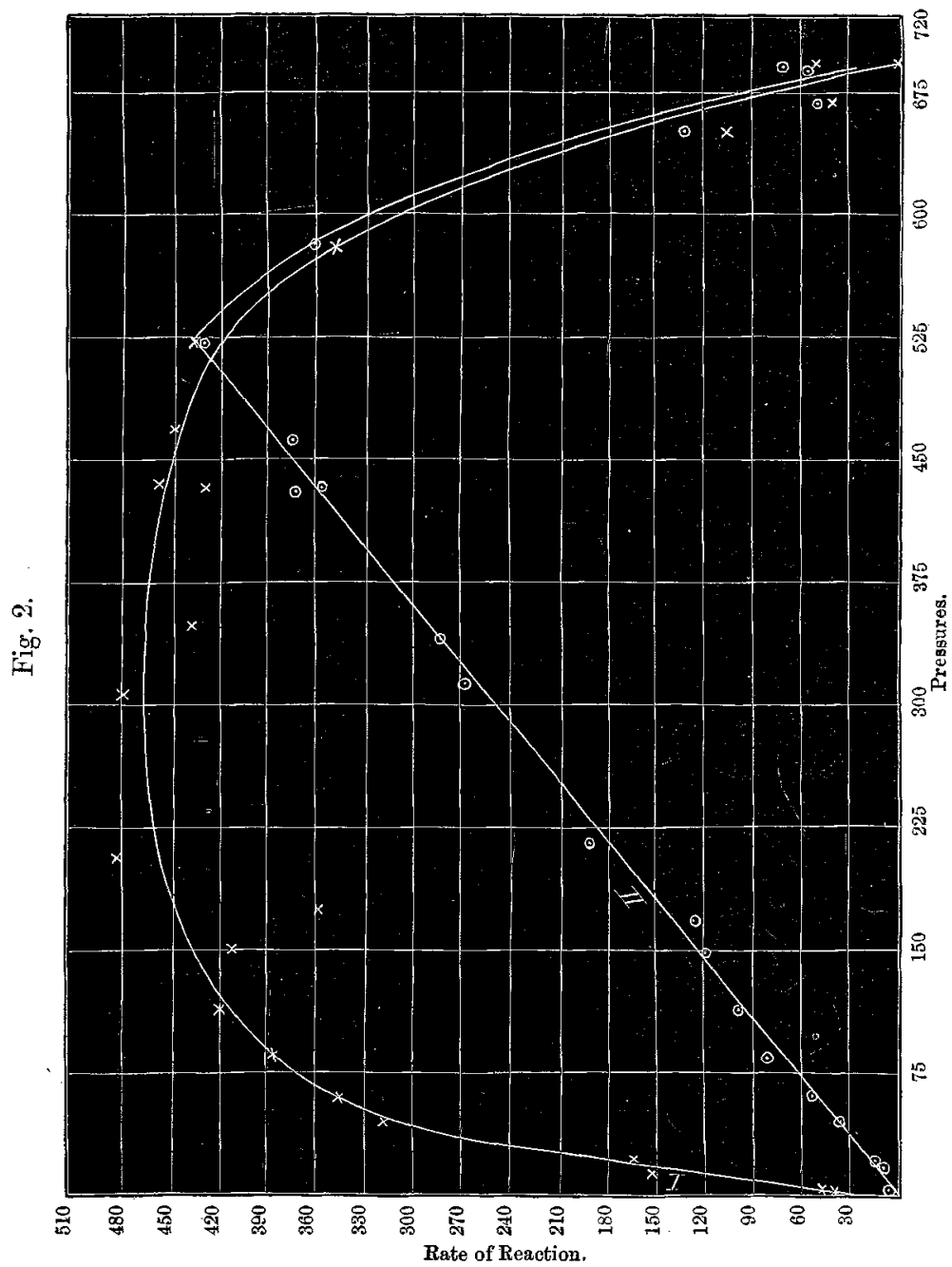

from those given in Table II., are not included in that Table, in order to avoid unnecessary complication. A glance at 
curve I. (fig. 2) will show that the velocity of the reaction beginning with the value 0 at 700 millim. increases at first very rapidly as the pressure falls, then varies between narrow limits over a considerable range of pressure (viz., from 500100 millim.), and finally decreases again rapidly. Curve II. (fig. 2) is obtained by dividing the values of $\frac{\Delta p}{\Delta t}$ from which curve $I$. is constructed by the corresponding values of $\log \frac{\mathrm{P}}{\mathrm{P}-p^{\prime}}$, the rate of evaporation of the phosphorus. That is, it represents the rate at which the reaction would go forward if the rate of evaporation of the phosphorus were constant. The numbers so obtained (represented in the figure by circles) evidently lie on a straight line passing through the origin. That is, the corrected velocities are proportional to the partial pressures of the oxygen. This, however, is only true up to a pressure of about 520 millim. At higher pressures the curve changes its direction, and the velocity very quickly decreases to 0 .

A more accurate way of testing the truth of this relationship is to be found in the calculation of the values of the constant $\mathrm{K}$ in equation $2 \mathrm{~b}$. On looking over the numbers given in Table II., it will be seen that the values of $K$ (at $20^{\circ}$ ) are approximately constant at pressures smaller than 550 millim. The numbers sometimes increase, sometimes decrease ; the variations may therefore be ascribed to experimental error.

The same is true for the experiments made at $30^{\circ}$, for pressures between 200 and 25 millim. (no measurements were made at pressures greater than 200 millim.). Below 25 millim., however, there is always a marked decrease in the values of $\mathrm{K}$, and traces of a similar behaviour are to be found in the experiments at $20^{\circ}$, and also in the one experiment at $9^{\circ}$. This diminution in the velocity of the reaction at low pressures may possibly have been due to the steam and nitrogen with which the oxygen was mixed hindering the interdiffusion of the oxygen and phosphorusvapour.

We may conclude, therefore, that wet oxygen at ordinary temperatures acts on phosphorus with a velocity which may be represented by the equation

$$
-\frac{d p}{d t}=\mathrm{K} \cdot p \cdot \log \frac{\mathrm{P}}{\mathrm{P}-p^{\prime}} .
$$


Above a certain limiting pressure (which probably varies with the temperature) this ceases to be true, the reaction taking place very much more slowly.

\section{Phosphorus and Dry Oxygen.}

Turning now to the action of dried oxygen on phosphorus quite a different result is obtained.

The experiments were made by the method and with the apparatus already described. The water in the glass vessel at A (fig. 1) was merely replaced by phosphorus pentoxide. In the first experiment the oxygen was allowed to remain in contact with the phosphorus pentoxide for a week, in the second, for two days. The numbers obtained are given in the following Table.

TABLE III.-Phosphorus and Dry Oxygen.

\begin{tabular}{|c|c|c|c|c|c|}
\hline \multicolumn{6}{|c|}{$\begin{array}{l}\text { Temperature }=20^{\circ} .87 \text { to } 21^{\circ} \cdot 26 \text {. } \\
\text { Pressure of phosphorus-vapour }=0.12 \text { millim. }\end{array}$} \\
\hline $\begin{array}{l}\text { Time in } \\
\text { minntes } \\
\text { from the } \\
\text { beginning. } \\
\quad t .\end{array}$ & $\begin{array}{l}\text { Total } \\
\text { pressure. } \\
\text { P. }\end{array}$ & $\begin{array}{l}\text { Partial } \\
\text { pressure of } \\
\text { Nitrogen. } \\
\quad(a)\end{array}$ & $\begin{array}{c}\text { Partial } \\
\text { pressure of } \\
\text { Oxygen. } \\
p\end{array}$ & $\mathbf{K}_{1}$ & K. \\
\hline $\begin{array}{r}0 \\
70\end{array}$ & $\begin{array}{l}433 \cdot 5 \\
433 \cdot 3\end{array}$ & $56 \cdot 5$ & $377 \cdot 0$ & & \\
\hline $\begin{array}{r}0 \\
15 \\
55 \\
110\end{array}$ & $\begin{array}{l}231 \cdot 9 \\
231 \cdot 9 \\
231 \cdot 5 \\
230 \cdot 5\end{array}$ & $\begin{array}{c}30 \cdot 3 \\
" \\
" \\
"\end{array}$ & $\begin{array}{l}201 \cdot 6 \\
201 \cdot 6 \\
201 \cdot 2 \\
200 \cdot 2\end{array}$ & 1.23 & \\
\hline $\begin{array}{l}0 \\
20 \\
120 \\
142 \\
161 \\
181 \cdot 5 \\
192 \\
204 \\
218 \\
227 \\
236 \\
253 \cdot 5\end{array}$ & $\begin{array}{r}122 \cdot 0 \\
117 \cdot 2 \\
86 \cdot 2 \\
78 \cdot 9 \\
71 \cdot 1 \\
62 \cdot 2 \\
57 \cdot 1 \\
50 \cdot 4 \\
36 \cdot 7 \\
34 \cdot 9 \\
26 \cdot 0 \\
21 \cdot 7\end{array}$ & $\begin{array}{l}160 \\
" \\
" \\
" \\
" \\
" \\
" \\
" \\
" \\
"\end{array}$ & $\begin{array}{r}106 \cdot 0 \\
101 \cdot 2 \\
70 \cdot 2 \\
62 \cdot 9 \\
55 \cdot 1 \\
46 \cdot 2 \\
41 \cdot 1 \\
34 \cdot 4 \\
20 \cdot 7 \\
18 \cdot 9 \\
10 \cdot 0 \\
5 \cdot 7\end{array}$ & $\begin{array}{l}23 \cdot 4 \\
27 \cdot 5 \\
27 \cdot 7 \\
28 \cdot 2 \\
29 \cdot 0 \\
29 \cdot 3 \\
30 \cdot 0 \\
32 \cdot 5 \\
31 \cdot 7 \\
33 \cdot 0 \\
31 \cdot 9\end{array}$ & $\begin{array}{l}2 \cdot 31 \\
2 \cdot 95 \\
3 \cdot 02 \\
3 \cdot 18 \\
3 \cdot 31 \\
3 \cdot 45 \\
3 \cdot 63 \\
4 \cdot 29 \\
4 \cdot 21 \\
4 \cdot 73 \\
4 \cdot 83\end{array}$ \\
\hline
\end{tabular}


of Phosphorus, Sulphur, and Aldehyde.

TABLE III.--Phosphorus and Dry Oxygen (continued).

\begin{tabular}{|c|c|c|c|c|c|}
\hline \multicolumn{6}{|c|}{$\begin{array}{l}\text { Temperature }=20^{\circ} \cdot 4 \text { to } 20^{\circ} .65 \text {. } \\
\text { Pressure of phosphorus-vapour }=1.035 \mathrm{~mm} \text {. bromnaphth. }\end{array}$} \\
\hline$t$. & $\begin{array}{c}\mathbf{P .} \\
\text { In millim. } \\
\text { of brom- } \\
\text { naphthalene }\end{array}$ & $\begin{array}{c}a . \\
\text { In millim. } \\
\text { of brom- } \\
\text { naphthalene. }\end{array}$ & $\begin{array}{l}p . \\
\text { In millim. } \\
\text { of mercury. }\end{array}$ & $\boldsymbol{K}_{1}$ & K. \\
\hline $\begin{array}{r}0 \\
18 \\
35\end{array}$ & $\begin{array}{l}1412 \cdot 8 \\
1395 \cdot 8 \\
1381 \cdot 5\end{array}$ & $\begin{array}{l}59 \cdot 4 \\
"\end{array}$ & $\begin{array}{l}150 \cdot 4 \\
148 \cdot 5 \\
146 \cdot 9\end{array}$ & $\begin{array}{l}35 \cdot 1 \\
32 \cdot 8\end{array}$ & \\
\hline $\begin{array}{r}0 \\
31 \\
45\end{array}$ & $\begin{array}{l}1082 \cdot 5 \\
1036 \cdot 0 \\
10127\end{array}$ & $\begin{array}{l}46 \cdot 7 \\
" \\
"\end{array}$ & $\begin{array}{l}115 \cdot 1 \\
109 \cdot 9 \\
107 \cdot 3\end{array}$ & $\begin{array}{r}45 \cdot 7 \\
48.9\end{array}$ & \\
\hline $\begin{array}{c}0 \\
10 \\
19 \\
21 \cdot 5 \\
35 \\
48 \cdot 5 \\
67 \\
106 \\
116 \\
127 \cdot 5\end{array}$ & $\begin{array}{l}608 \cdot 0 \\
589 \cdot 0 \\
566 \cdot 0 \\
561 \cdot 0 \\
531 \cdot 5 \\
498 \cdot 5 \\
451 \cdot 5 \\
347 \cdot 0 \\
313 \cdot 0 \\
270 \cdot 0\end{array}$ & $\begin{array}{c}28 \cdot 0 \\
" \\
" \\
" \\
" \\
" \\
" \\
" \\
"\end{array}$ & $\begin{array}{l}64 \cdot 4 \\
62 \cdot 3 \\
59 \cdot 8 \\
59 \cdot 2 \\
55 \cdot 9 \\
52 \cdot 3 \\
47 \cdot 1 \\
35 \cdot 4 \\
31 \cdot 7 \\
26 \cdot 9\end{array}$ & $\begin{array}{l}46 \cdot 0 \\
52 \cdot 9 \\
52 \cdot 2 \\
51 \cdot 6 \\
52 \cdot 4 \\
53 \cdot 2 \\
53 \cdot 4 \\
54 \cdot 2 \\
55 \cdot 1\end{array}$ & $\begin{array}{l}1 \cdot 93 \\
2 \cdot 23 \\
2 \cdot 21 \\
2 \cdot 22 \\
2 \cdot 29 \\
2 \cdot 38 \\
2 \cdot 53 \\
2 \cdot 62 \\
2 \cdot 74\end{array}$ \\
\hline
\end{tabular}

The reaction now first began at a much lower pressure than formerly. Under a pressure of oxygen of 377 millim. it did not begin ; it just began when the pressure was reduced to 202 millim. Curve I. (fig. 3) shows the connexion between

Fig. 3.-Phosphorus and Dry Oxygen.

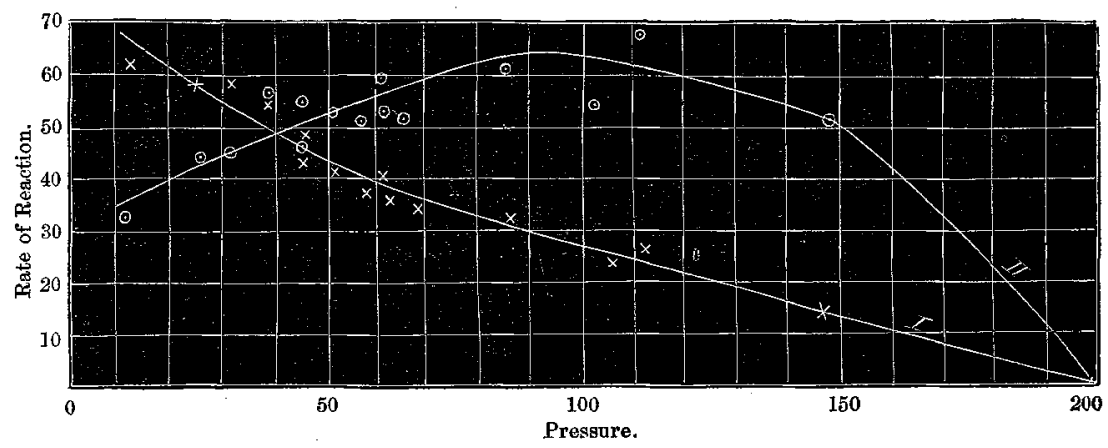

the pressure of the oxygen and the velocity with which it acts on the phosphorus. The curve is constructed from the figures given in Table III. in the same way as before. Setting 
out from the pressure of 200 millim., at which the velocity of the reaction is 0 , it appears to increase continuously as the pressure falls, and not to reach a maximum value as is the case when the gas is moist. Curve II. (fig. 3) is obtained by dividing the values of the rate of reaction from which curve $I$. is drawn by the corresponding values of the rate of evaporation of the phosphorus, and plotting the numbers so obtained against the pressures. The numbers are so irregular that it is not easy to make out the true nature of the curve. The values of the ordinates of the part of the curve between 0 and 70 millim., however, appear to be proportional to the square roots of the corresponding values of the pressure.

We have, accordingly,

$$
-\frac{d p}{d t}=\mathrm{K}_{1} p^{\frac{1}{2}} \log \frac{\mathrm{P}}{\mathrm{P}-p^{\prime}}, \quad . \quad . \quad . \quad .
$$

which is the same equation as has already been found to hold good for phosphorus and moist oxygen, except that the velocity of the reaction is put proportional to the square root of the partial pressure of the oxygen instead of to the pressure itself.

This equation may be integrated by expanding the logarithm in the same way as before: this gives, neglecting small terms,

$$
-\mathrm{K}_{1} t=\frac{2}{3 p^{\prime}}(\mathrm{P}-a)^{\frac{3}{2}}+\left(\frac{2 a}{p^{\prime}}-1\right)(\mathrm{P}-a)^{\frac{7}{3}}+\text { const. }
$$

The value of the constant is obtained from the condition that $\mathrm{P}=\mathrm{P}_{0}$, when $t=0 ; \mathrm{P}_{0}$ being the total pressure at the beginning of the experiment. Introducing the value of the constant, we obtain

$\mathrm{K}_{1} t=\frac{2}{3 p^{\prime}}\left[\left(\mathrm{P}_{0}-a\right)^{\frac{3}{2}}-(\mathrm{P}-a)^{\frac{3}{2}}\right]+\left(\frac{2 a}{p^{\prime}}-1\right)\left[\left(\mathrm{P}_{0}-a\right)^{\frac{3}{2}}-(\mathrm{P}-a)^{\frac{1}{2}}\right]$.

$\mathrm{It}$ is by means of this expression that the values of $\mathrm{K}_{1}$ given in Table III. have been calculated. The numbers show that $K_{1}$ is approximately constant from a pressure of 60-70 millim. downwards; at higher pressures it diminishes. The irregularity of the numbers is probably due, in part at any rate, to the deposition of a coating of oxide on the surface of the phosphorus. We may therefore say that the rate of evaporation of the phosphorus heing supposed constant, it is acted on by dry oxygen with a velocity which is proportional to the square root of its pressure. This is only true (at $20^{\circ}$ ) up to a pressure of some 60-70 millim.; above this pressure the velocity decreases. It is of interest that the greatest 
velocity of the reaction occurs in this case at very nearly the same pressure as that which van't Hoff found to be most favourable to the reaction between phosphine and oxygen.

In Table III. the values of $\mathrm{K}$ calculated from equation ( 26$)$ (in which the rate of reaction is put proportional to the pressure) are also given. They are much less constant than the values of $K_{1}$.

\section{SUlPHUR AND OXYGEN.}

The course of this reaction is more regular than that of the last, because the products of oxidation being volatile the surface of the sulphur remains unchanged.

The first experiments were made by a method similar to that which was used with phosphorus, the volume being kept constant and the pressure allowed to change. The essential part of the apparatus is shown in fig. 4. It consisted of a

Fig. 4.

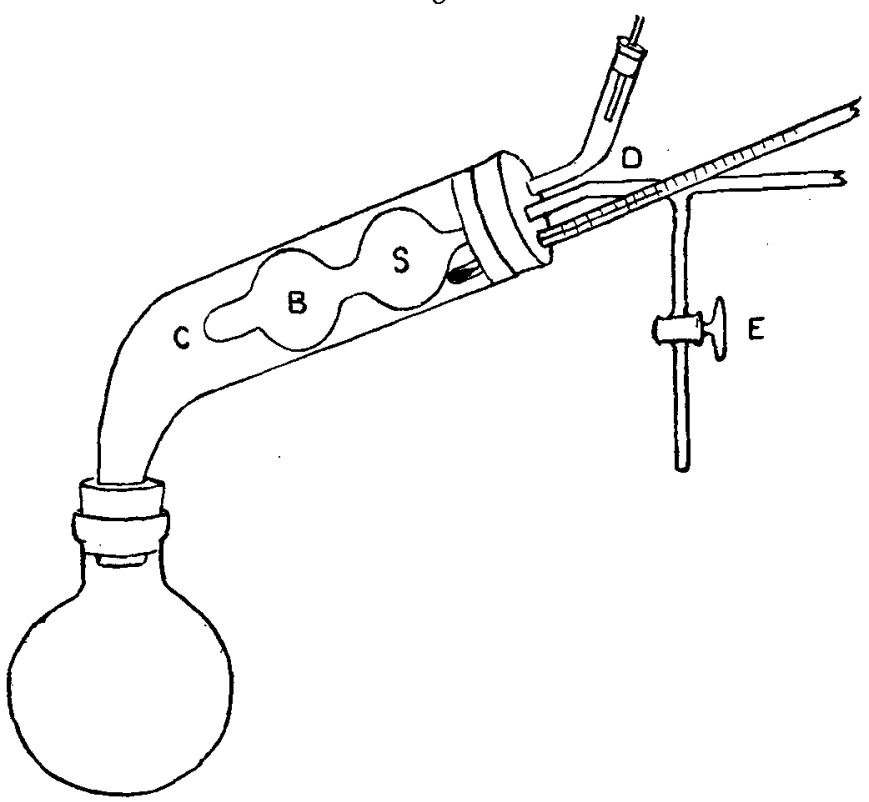

tube with two bulbs blown upon it, B, S, and of 60-70 cubic centim. capacity. At $S, 1-2$ grams of pure sulphur, at $B$, 5-6 grams of soda-lime were placed, and the end C sealed up before the blowpipe. The capillary-tube $D$ connected the apparatus with a manometer, and with the tap $\mathrm{E}$, by means of which it was filled with oxygen. The whole was heated Phil. Mag. S. \%. Vol. 38. No. 235. Dec. 1894. $2 \mathrm{~N}$ 
to a temperature of about $160^{\circ}$ in the vapour of boiling turpentine. The following Table contains the results of an experiment made by this method.

TABLe IV.-Sulphur and Oxygen.

Temperature $=156^{\circ}$.

Vapour-pressure of sulphur $=11.5$ millim. ${ }^{*}$

Pressure of nitrogen . . $=8.1$ millim.

\begin{tabular}{|c|c|c|c|}
\hline $\begin{array}{c}\text { Time in minutes } \\
\text { from beginning. } \\
t .\end{array}$ & $\begin{array}{c}\text { Total pressure. } \\
\mathbf{P .}\end{array}$ & $\begin{array}{c}\text { Partial pressure } \\
\text { of Oxygen } \\
=p .\end{array}$ & $\mathbf{K}_{1}$. \\
\hline 0 & $132 \cdot 5$ & $114 \cdot 0$ & \\
18 & $121 \cdot 0$ & $102 \cdot 5$ & 74 \\
41 & $107 \cdot 2$ & $88 \cdot 7$ & 64 \\
58 & $93 \cdot 4$ & $74 \cdot 9$ & 65 \\
75 & $79 \cdot 9$ & $61 \cdot 4$ & 63 \\
84 & $71 \cdot 6$ & $53 \cdot 1$ & 65 \\
97 & 587 & $40 \cdot 2$ & 65 \\
107 & $47 \cdot 6$ & $29 \cdot 1$ & 65 \\
119 & $30 \cdot 0$ & $11 \cdot 5$ & 65 \\
128 & $20 \cdot 0$ & $1 \cdot 5$ & 63 \\
\hline
\end{tabular}

$\mathrm{K}_{1}$ was calculated from the equation obtained by the integration of equation 3 . Owing to the magnitude of $p^{\prime}$, equation $(3 a)$ is insufficiently accurate, and two further terms of the expansion of the logarithm have to be included. The equation thus obtained is :-

$$
\begin{aligned}
-\mathrm{K}_{1} t=\frac{2}{3 p^{\prime}}(\mathrm{P}-a)^{\frac{3}{2}}+\left(\frac{2 a}{p^{\prime}}-1-\frac{p^{2}}{24 a \mathrm{P}}\right) & (\mathrm{P}-a)^{\frac{1}{2}} \\
& -\frac{p^{\prime}}{6 \sqrt{a}} \tan ^{-1}\left(\frac{\mathrm{P}-a}{a}\right)^{\frac{1}{3}} \\
& -\frac{p^{2}}{24 a^{\frac{3}{3}}} \sin ^{-1}\left(\frac{\mathrm{P}-a}{\mathrm{P}}\right)^{\frac{3}{2}} \\
& + \text { const. }
\end{aligned}
$$

The integration-constant is determined as before. With the exception of the first number, the values of $K_{1}$ are very satisfactorily constant; equation (3) therefore applies also to this reaction.

* On further heating pressure remained constant at 18.5 millim. ; after cooling pressure $=5.4$ millim. at $12^{\circ}$. From which pressure of the sylphur-vapour $=10.4$ millim. Another experiment gave 12.6 millim. 
It was found that more satisfactory results could be obtained by using a different method, in which the pressure was kept constant and the diminution of volume measured. This method has the advantage that it allows several measurements of the velocity to be made at each pressure; by this means accidental variations can be eliminated. It was noticed, for example, almost invariably that at the beginning of an experiment (the pressure being constant) the rate at which the volume diminished was not constant. The reaction commenced too fast, and only reached a constant velocity after some time. This doubtless accounts for the abnormally large value of $K_{1}$ at the beginning of the experiment in Table IV.

The apparatus finally adopted is shown in fig. 5 .

Fig. 5.

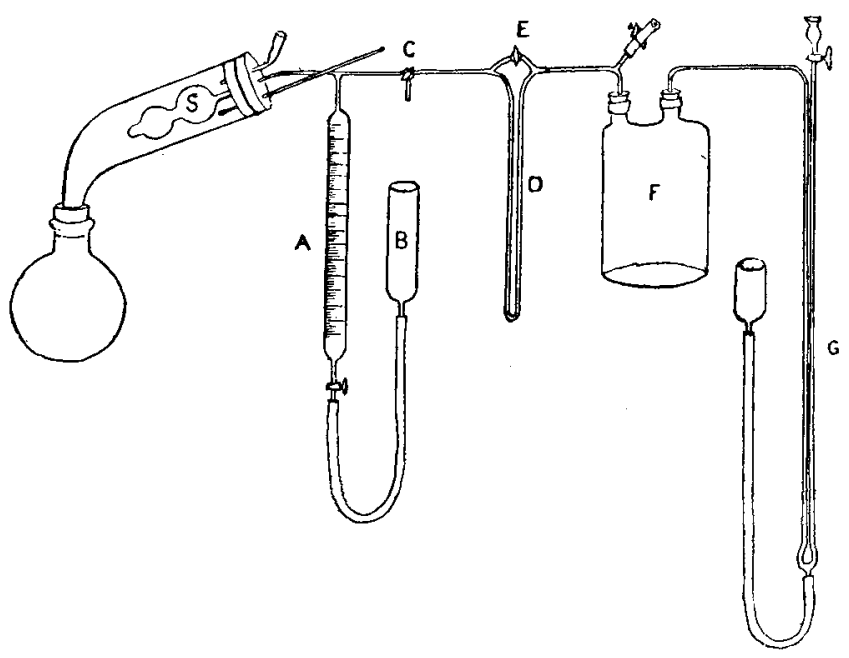

The tube $\mathrm{S}$ containing the sulphur and oxygen remains unchanged. It was attached to a graduated tube A, containing mercury, the height of which could be changed by means of the reservoir $B$. $C$ is a three-way tap; D a sensitive gauge containing bromnaphthalene, it serves to show when the pressure in the part of the apparatus to its left is equal to that in the reservoir $F$. The tap $\mathrm{E}$ serves to put the parts of the apparatus to the right and to the left of $D$ in communication with each other when necessary. The reservoir F, which serves to keep the pressure constant, is in communication with the manometer $G$ and with an air-pump. $2 \mathrm{~N}_{2}$ 
The part of the apparatus to the left of $\mathrm{D}$ having been filled with oxygen at a somewhat greater pressure than exists in $\mathrm{F}$, the $\operatorname{tap} \mathrm{E}$ is opened for a moment to equalize the pressure on both sides of $D$, and the position of the mercury in $A$ read off. By raising $B$ the pressure of the oxygen can always be kept equal to the constant pressure in F. The diminution of volume per minute, when reduced to standard pressure, is then proportional to the velocity of the reaction. When the velocity has become constant, the pressure in $F$ is reduced, the tap E opened to equalize the pressure again, and further readings made at the new pressure.

The following Table contains the numbers obtained by this method.

In it $\frac{\Delta v}{\Delta t}$ is the diminution of the volume per minute, the volume being measured at pressure $P$.

$\frac{d v}{d t}$ is the rate of change of the volume, calculated for a pressure of $819 \cdot 7$ millim., and it is proportional to the quantity of oxygen which is converted into sulphur dioxide per minute, that is to the rate of the reaction.

TABLe V.-Sulphur and Oxygen.

\begin{tabular}{|c|c|c|c|c|c|}
\hline $\begin{array}{c}\text { Pressure. } \\
\text { P. }\end{array}$ & $\frac{\Delta v}{\Delta t}$. & $\frac{d v}{d t}$ & $\begin{array}{l}\text { Tempera- } \\
\text { ture. }\end{array}$ & $\mathbf{K}_{2}$ & $k$. \\
\hline $\begin{array}{r}809 \cdot 8 \\
587 \cdot 0 \\
380 \cdot 6 \\
198 \cdot 5 \\
105 \cdot 6 \\
43 \cdot 8\end{array}$ & $\begin{array}{c}\cdot 0176 \\
\cdot 0244 \\
\cdot 0459 \\
\cdot 147 \\
\cdot 456 \\
1 \cdot 77\end{array}$ & $\begin{array}{l}.0174 \\
.0175 \\
.0213 \\
.0356 \\
.0588 \\
.0946\end{array}$ & $\begin{array}{l}158 \\
158 \\
158 \\
159 \\
159 \\
159\end{array}$ & $\begin{array}{l}.0985 \\
.0841 \\
.0820 \\
.0975 \\
.118 \\
\cdot 108\end{array}$ & $\begin{array}{l}.0035 \\
.0035 \\
.0042 \\
.0069 \\
.0156 \\
.0163\end{array}$ \\
\hline $\begin{array}{r}819 \cdot 7 \\
578.7 \\
422.2 \\
306.0 \\
194.0 \\
147.3 \\
95.9 \\
41.8\end{array}$ & $\begin{array}{l}\cdot 0149 \\
.0243 \\
.0349 \\
\cdot 0653 \\
\cdot 133 \\
\cdot 222 \\
\cdot 455 \\
1 \cdot 84\end{array}$ & $\begin{array}{l}.0149 \\
.0172 \\
.0180 \\
.0244 \\
.0315 \\
.0399 \\
.0532 \\
.0938\end{array}$ & $\begin{array}{c}158 \\
159 \\
159 \\
159 \cdot 5 \\
159 \cdot 2 \\
159 \cdot 4 \\
",\end{array}$ & $\begin{array}{l}.085 \\
.082 \\
.088 \\
.084 \\
.085 \\
.093 \\
.098 \\
.104\end{array}$ & $\begin{array}{r}.0030 \\
.0034 \\
.0043 \\
.0048 \\
.0061 \\
.0077 \\
.0100 \\
.0161\end{array}$ \\
\hline
\end{tabular}

The constant $K_{2}$ is calculated from the following equation, which is essentially identical with equation $3:-$

$$
-\frac{d v}{d t}=\mathrm{K}_{2} \mathrm{P}^{\frac{1}{2}} \log \frac{\mathrm{P}}{\mathrm{P}-p^{\prime}} .
$$


of Phosphoris, Sulphur, and Aldehyde.

$k$ (Table V.) is calculated by the formula

$$
-\frac{d v}{d t}=k \mathrm{P} \log \frac{\mathrm{P}}{\mathrm{P}-p^{\prime}} .
$$

It is evident that the formula in which the velocity of the reaction is put proportional to the square root of the pressure is in much better agreement with the truth than that in which it is put proportional to the pressure itself.

The curves in fig. 6 represent the connexion between the

Fig. 6.--Sulphur and Oxygen.

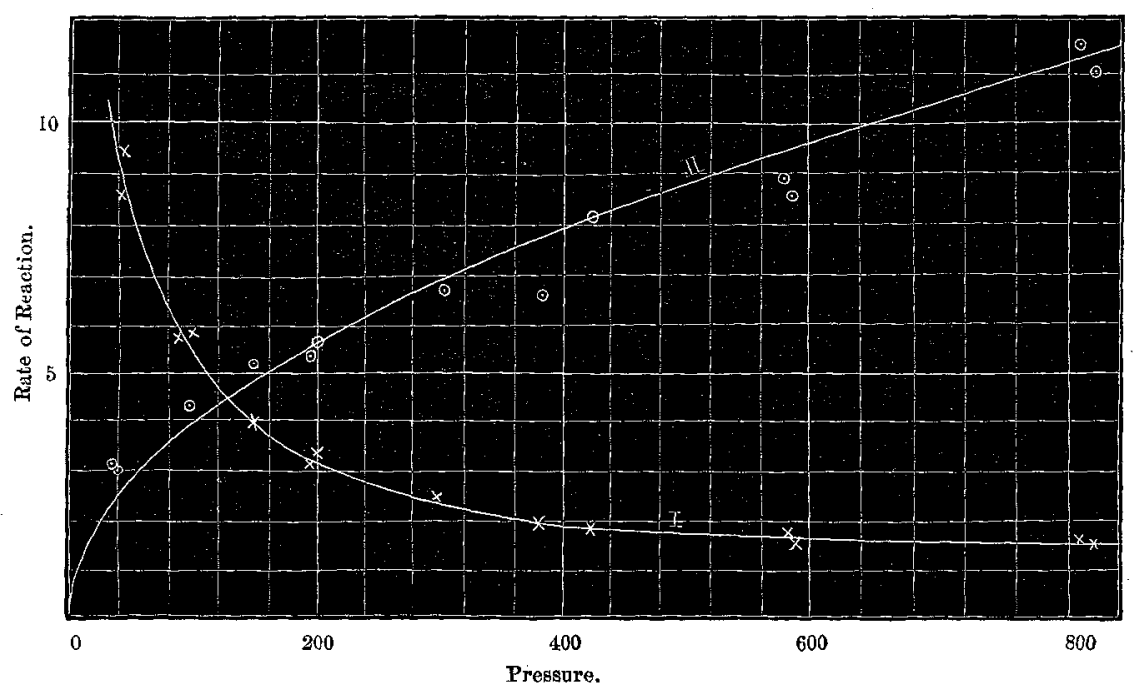

velocity of the reaction and the pressure. Curve $I$. is drawn with the values of $\frac{d v}{d t}$ as ordinates and pressures as abscissæ. It has a strong general resemblance to the curve representing the velocity of the reaction between phosphorus and dry oxygen. The velocity continuously increases as the pressure falls. Curve II. is drawn with ordinates proportional to the square roots of the corresponding pressures. The experimental values of the velocity of the reaction corrected for the rate of evaporation of the sulphur, viz. :

$$
\frac{d v}{d t} / \log \frac{\mathrm{P}}{\mathrm{P}-\mathrm{p}^{\prime}}
$$


are represented in the figure by circles. The theoretical curve evidently represents these points with fair approximation.

It is interesting to notice that the whole curve here, up to 800 millim., corresponds to the part of the curve for phosphorus and dry oxygen between 0 and 70 millim. It would be of interest to make experiments with sulphur and oxygen at higher pressures in order to find ont whether a maximum velocity occurs similar to that found with phosphorus.

\section{ALDEHYDE AND OXYGEN.}

When, as in the experiments which have just been described, the substance which is undergoing oxidation is a solid or a liquid, its rate of evaporation becomes such an important factor in determining the rate of the reaction, that it is not easy to make out with perfect certainty what rôle is played by the concentration of the oxygen. It appears, however, very probable that in dry oxygen the rate of the reaction is proportional to the square root of its concentration. In order to further test the truth of this result, experiments were made on the reaction between aldehyde-vapour and oxygen. The reaction was found to go on with convenient speed at $20^{\circ}$. As aldehyde boils at $21^{\circ}$ under a pressure of 760 millim., it was assumed that aldehyde-vapour at $20^{\circ}$ and under pressures not exceeding 550 millim. might be regarded with sufficient approximation as a perfect gas. Numerous attempts were made to absorb the acetic acid formed, by means of some solid substance without action on the aldehyde. $\mathrm{PbO}, \mathrm{ZnO}, \mathrm{BaCO}_{3}, \mathrm{KC}_{2} \mathrm{H}_{3} \mathrm{O}_{2}$ (anhydrous), were tried, but they all appeared to cause a more or less rapid diminution in the quantity of the aldehyde-rapour. The experiments were therefore made without any such absorbent.

The apparatus used (fig. 7) was essentially the same as that which was employed by van't Hoff for the study of the formation of water from electrolytic gas (Etudes de dyn. chimique, p. 53), and for the study of the decomposition by heat of $\mathrm{PH}_{3}$ and $\mathrm{AsH}_{3}$. The reaction takes place in the bulb $\mathrm{A}$ (fig. 7 ): this has a capacity of 60 to 70 cubic centim., and is immersed in a water-bath maintained at a constant temperature. The tubes connecting A to the rest of the apparatus, which are not plunged in the water, are made of capillary diameter in order to diminish as far as possible the volume of gas which is at the temperature of the air. The pressure of the gas in the apparatus is determined by means of the manometer B CD. By raising or lowering the tube $C_{\text {; }}$ the level of the mercury 
was always brought to $B$ before a reading was made. The pressure of the gas in the apparatus is then obtained by reading the difference in level between $B$ and $D$ : for this purpose a vertical millimetre-scale was generally used, sometimes a cathetometer.

$\mathrm{CD}$ is a barometer, the lower end of which just dips under the mercury at $\mathrm{C}$. The air-trap at $\mathrm{E}$ is useful in preventing bubbles of air, which sometimes leak through the indiarubber tube, from passing back into the apparatus.

By means of the three-way tap $H$ the apparatus can be connected either with an air-pump through $\mathrm{F}$, or with a little vessel containing liquid aldehyde $(G)$, which is ground to fit the lower limb of the tap. The apparatus having been

Fig. 7.



evacuated as completely as possible, the tap is turned so that the aldehyde-vapour distils into it. By repeating this operation several times, the air may be completely replaced by aldehyde-vapour at any desired pressure up to 500-600 millim. This having been done the tap $H$ is closed, the apparatus put in position in the water-bath, and the pressure of the aldehydevapour observed. $\mathrm{F}$ is then connected with a tube delivering pure oxygen dried over $\mathrm{CaCl}_{2}$, which is allowed to flow 
through FH until it is full of oxygen. The tap $\mathrm{H}$ is then quickly opened, to admit the oxygen, closed a gain, and the pressure read off. Further readings are then made from time to time until the reaction is ended. The gases take some time to diffuse into each other, so that the velocity of the reaction was frequently rather small at the beginning.

The calculation of the experiments required a knowledge of the composition of the gas which remained in the apparatus at the end of the experiment. As soon as the last reading of the pressure had been made, therefore, a very dilute solution of caustic potash was allowed to flow into the apparatus from a weighed flask. The difference between the volume of the apparatus (determined by weighing it full of water) and the volume of the caustic-potash solution drawn into it, gave the volume of oxygen and nitrogen contained in the residue. Caustic potash was used in order to polymerize any aldehyde left.

The mixture of oxygen and nitrogen was then transferred to a graduated tube, and shaken with an alkaline solution of pyrogallol. The part which was left unabsorbed was taken to be nitrogen. The transference of the residual gas from the bulb $A$ to the graduated tube was effected by running water in through the capillary tube $\mathrm{K}$ after breaking off its sealed end.

In many of the earlier experiments a comparatively large quantity of gas remained which was not absorbed by the solution of pyrogallol and caustic potash. It was noticed, however, finally that this gas was inflammable, and that its formation was accompanied by some action of the mixture of aldehyde and oxygen on the mercury in the manometer, a white substance; which was insoluble in water, being formed.

On protecting the mercury by placing a very small quantity of bromnaphthalene over its surface, no formation of the white substance occurred, and the gas which remained unacted upon by the pyrogallol was much smaller in quantity than formerly, and no longer inflammable. It is probable also that the reaction is accelerated by light. The following experiment may be quoted in support of this view. The temperature was $19^{\circ} .98$ to $20^{\circ} .07$.

The constant $K$ was calculated by means of equation (5), which was found to apply to this reaction. The value of the constant appears to be influenced by the brightness of the light. For this reason the experiments were finally made in the dark. It appears also to be of some importance to keep the apparatus as clean as possible. It was generally allowed 
to remain over night filled with a solution iof potassium permanganate and hydrochloric acid. The manganese dioxide formed was removed by means of oxalic acid; the apparatus was then well washed with distilled water and dried by a current of air.

\begin{tabular}{|c|c|c|c|c|}
\hline Time. & $\begin{array}{c}\text { Pressure of } \\
\text { Oxygen. } \\
p_{1} .\end{array}$ & $\begin{array}{c}\text { Pressure of } \\
\text { Aldehyde. } \\
p_{2}\end{array}$ & K. & Remarks. \\
\hline $\begin{array}{l}11.26 \text { A.M. } \\
11.50 \text { " } \\
12.21 \text { P.M. } \\
2.33 ", \\
3.6 \% " \\
3.56 ", \\
7.8 ", \\
8.17 ",\end{array}$ & $\begin{array}{r}196 \cdot 8 \\
182 \cdot 0 \\
160 \cdot 4 \\
86 \cdot 3 \\
72 \cdot 8 \\
57 \cdot 5 \\
28 \cdot 7 \\
23 \cdot 7\end{array}$ & $\begin{array}{l}543 \cdot 2 \\
510 \cdot 2 \\
457 \cdot 6 \\
269 \cdot 5 \\
241 \cdot 3 \\
211 \cdot 2 \\
158 \cdot 1 \\
149 \cdot 1\end{array}$ & $\begin{array}{l}0.76 \\
0.89 \\
1 \cdot 19 \\
1.24 \\
1.27 \\
1.20 \\
1.08\end{array}$ & $\begin{array}{l}\text { Oloudy. } \\
\quad " \\
\begin{array}{l}\text { Direct sunlight } \\
\text { on apparatus. }\end{array} \\
\text { Nearly dark. }\end{array}$ \\
\hline
\end{tabular}

The following Table contains the results of the experiments which were made with the precautions mentioned :-

Tabie VI.-Aldehyde and Oxygen.

\begin{tabular}{|c|c|c|c|c|}
\hline $\begin{array}{c}\text { Time in } \\
\text { minutes from } \\
\text { the beginning. } \\
t .\end{array}$ & $\begin{array}{l}\text { Pressure } \\
\text { of } \\
\text { Oxygen. } \\
p_{k^{*}}\end{array}$ & $\begin{array}{c}\text { Pressure } \\
\text { of: } \\
\text { Aldehydo. } \\
p_{2^{*}}\end{array}$ & $\begin{array}{c}\text { Total } \\
\text { pressure. } \\
\text { P. }\end{array}$ & $\mathrm{K} \times 10^{5}$ \\
\hline $\begin{array}{r}0 \\
67 \\
117 \\
190 \\
259 \\
270 \\
296 \\
332 \\
386 \\
476 \\
673 \\
1303\end{array}$ & $\begin{array}{r}225 \cdot 8 \\
210 \cdot 3 \\
200 \cdot 5 \\
188 \cdot 1 \\
177 \cdot 1 \\
174 \cdot 6 \\
167 \cdot 2 \\
161 \cdot 4 \\
150 \cdot 7 \\
136 \cdot 6 \\
118 \cdot 3 \\
83.8\end{array}$ & $\begin{array}{l}536 \cdot 0 \\
499 \cdot 1 \\
466 \cdot 9 \\
427 \cdot 3 \\
395 \cdot 8 \\
388 \cdot 8 \\
368 \cdot 7 \\
353 \cdot 5 \\
324 \cdot 7 \\
292 \cdot 3 \\
251 \cdot 6 \\
183 \cdot 1\end{array}$ & $\begin{array}{l}785 \cdot 0 \\
744 \cdot 5 \\
702 \cdot 5 \\
651 \cdot 5 \\
608 \cdot 0 \\
598 \cdot 5 \\
571 \cdot 0 \\
550 \cdot 0 \\
510 \cdot 5 \\
464 \cdot 0 \\
405 \cdot 0 \\
302 \cdot 0\end{array}$ & $\begin{array}{l}2 \cdot 91 \\
2 \cdot 94 \\
2 \cdot 81 \\
2 \cdot 84 \\
2 \cdot 93 \\
3 \cdot 16 \\
3 \cdot 19 \\
3 \cdot 43 \\
3 \cdot 57 \\
3 \cdot 40 \\
3 \cdot 29\end{array}$ \\
\hline $\begin{array}{l}\text { Partial pre } \\
\text { Partial pre } \\
\text { Total pres } \\
\text { Vapour-pr }\end{array}$ & $\begin{array}{l}\text { Temp } \\
\text { ure of oxy } \\
\text { are of nitro } \\
\theta \text { at the en } \\
\text { ure of acet }\end{array}$ & $\begin{array}{l}\text { ure }=20^{\circ} \\
\text { at the end } \\
\text { at the end } \\
\text { the experix } \\
\text { cid at } 20^{\circ} \cdot \\
y^{\prime}=0.00287\end{array}$ & $\begin{array}{l}0^{\circ} \cdot 32 . \\
\text { eriment }= \\
\text { eriment }= \\
\cdot . \quad \cdot= \\
\cdot \quad \cdot=\end{array}$ & $\begin{array}{c}\text { millim. } \\
", \\
" \prime\end{array}$ \\
\hline
\end{tabular}


Table VI. (continued).

\begin{tabular}{|c|c|c|c|c|}
\hline $\begin{array}{c}\text { Time in } \\
\text { minutes from } \\
\text { the beginning. } \\
t .\end{array}$ & $\begin{array}{l}\text { Pressure } \\
\text { of } \\
\text { Oxygen. } \\
p_{1} .\end{array}$ & $\begin{array}{c}\text { Pressure } \\
\text { of } \\
\text { Aldehyde. } \\
p_{2} .\end{array}$ & $\begin{array}{c}\text { Total } \\
\text { pressure. } \\
\text { P. }\end{array}$ & $\mathbf{K} \times 10^{5}$ \\
\hline $\begin{array}{r}0 \\
72 \\
98 \\
132 \\
163 \\
229 \\
325 \\
464 \\
617 \\
1330\end{array}$ & $\begin{array}{l}489 \cdot 6 \\
485 \cdot 3 \\
480 \cdot 6 \\
475 \cdot 5 \\
470 \cdot 0 \\
457 \cdot 2 \\
441 \cdot 6 \\
424 \cdot 2 \\
409 \cdot 1 \\
376 \cdot 5\end{array}$ & $\begin{array}{r}291 \cdot 2 \\
281 \cdot 7 \\
273 \cdot 2 \\
251 \cdot 2 \\
249 \cdot 2 \\
220 \cdot 5 \\
186 \cdot 1 \\
159 \cdot 5 \\
119 \cdot 1 \\
57 \cdot 2\end{array}$ & $\begin{array}{l}799 \cdot 0 \\
790 \cdot 5 \\
781 \cdot 0 \\
766 \cdot 5 \\
749 \cdot 0 \\
707.5 \\
657 \cdot 5 \\
603.5 \\
558 \cdot 0 \\
463.5\end{array}$ & $\begin{array}{l}0.96 \\
1.52 \\
1.81 \\
2 \cdot 05 \\
2 \cdot 87 \\
2 \cdot 94 \\
3 \cdot 11 \\
3 \cdot 18 \\
3 \cdot 00\end{array}$ \\
\hline \multicolumn{5}{|c|}{$\begin{array}{l}\text { Temperature }=20^{\circ} \cdot 5 \mathrm{t} \\
\text { Total pressure of residual gas } \cdot . \cdot . \\
\text { Partial pressure of residual oxygen. } \cdot . \\
\text { Partial pressure of residual nitrogen } . \\
\text { Vapour-preseure of acetic acid at } 20^{\circ} \cdot 6 . \\
\qquad k^{\prime}=0.00103 .\end{array}$} \\
\hline$t$ & $p_{1}$. & $p_{2}$ & P. & $\mathbf{K} \times 10^{5}$ \\
\hline $\begin{array}{r}0 \\
146\end{array}$ & $\begin{array}{c}5957 \\
\ldots \ldots\end{array}$ & $\begin{array}{c}270 \cdot 0 \\
\cdots \cdots . .\end{array}$ & $\begin{array}{l}878 \cdot 0 \\
878 \cdot 0\end{array}$ & \\
\hline $\begin{array}{r}0 \\
136 \\
1163\end{array}$ & $\begin{array}{c}533 \cdot 2 \\
532 \cdot 3 \\
\check{532 \cdot 3}\end{array}$ & $\begin{array}{l}241 \cdot 6 \\
239 \cdot 9 \\
239 \cdot 7\end{array}$ & $\begin{array}{l}785 \cdot 7 \\
783 \cdot 1 \\
782 \cdot 9\end{array}$ & \\
\hline $\begin{array}{r}0 \\
353 \\
421 \\
501 \\
\end{array}$ & $\begin{array}{l}373 \cdot 0 \\
346 \cdot 8 \\
344 \cdot 6 \\
342 \cdot 7 \\
\end{array}$ & $\begin{array}{l}178 \cdot 5 \\
122 \cdot 8 \\
118 \cdot 2 \\
114 \cdot 2 \\
\end{array}$ & $\begin{array}{l}559 \cdot 3 \\
488 \cdot 8 \\
481 \cdot 8 \\
476 \cdot 1 \\
\end{array}$ & $\begin{array}{r}2 \cdot 82 \\
2559 \\
2 \cdot 34 \\
\end{array}$ \\
\hline \multicolumn{5}{|c|}{ 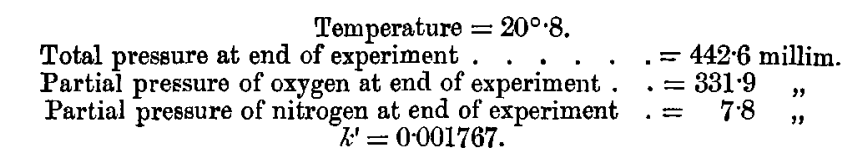 } \\
\hline
\end{tabular}

Another experiment at $21^{\circ} .4$ gave no reaction when the pressure of the oxygen was 599 millim., and also when it was reduced to 530 millim. the reaction did not begin.

The calculation of the amount of change which had occurred at any moment, from the change of pressure, is complicated by the solvent action of the liquid acetic acid formed on the aldehyde-vapour : owing to this the amount of change at any 
given moment is not simply proportional to the diminution of the pressure.

Suppose that at the commencement of the experiment, the partial pressure of the aldehyde were $=a$ millim., that of the oxygen $=b$ millim., and that of the nitrogen $=\mathrm{N}$ millim. And let $\mathrm{P}$ be the total pressure of the gas at any time, $t$ minutes after the beginning of the experiment. Suppose also that at the same instant $c$ millim. of oxygen have united with $2 x$ millim. of aldehyde. At first the acetic acid formed remains as vapour, and as its density at $20^{\circ}$ is double the normal value, we shall have 2 volumes of aldehyde-vapour and 1 volume of oxygen condensing to form 1 volume of acetic-acid vapour. That is, the acetic-acid vapour will occupy the same volume and exert the same pressure as the oxygen from which it is formed; and the pressure of the mixture will be

$$
\begin{aligned}
\mathrm{P} & =(a-2 x)+(b-x)+x+\mathrm{N} \\
& =a+b-2 x+\mathrm{N} .
\end{aligned}
$$

The pressure at the beginning of the experiment $\left(\mathbf{P}_{0}\right)$ was equal to $a+b+\mathrm{N}$, so that we obtain

$$
2 x=\mathrm{P}_{0}-\mathrm{P} \text {. }
$$

After a time the acetic-acid vapour will reach its maximum pressure (say $m$ ), after which liquid acetic acid will be formed, and its quantity will be proportional to $(x-m)$, that is $=k(x-m)$. If we assume that the quantity of aldehyde dissolved in the acetic acid follows Henry's law, it will be proportional to the pressure of the gaseous aldehyde and to the quantity of liquid acetic acid; that is, to $k^{\prime}(x-m) p_{2}$, where $p_{2}$ is the pressure of the aldehyde-vapour.

The pressure of the aldehyde-vapour at any moment is its original pressure diminished by the part which has undergone chemical reaction and by the. part dissolved in the acetic acid; that is

or

$$
p_{2}=a-2 x-k^{\prime}(x-m) p_{2},
$$

$$
p_{2}=\frac{a-2 x}{1+k^{\prime}(x-m)} \cdot \text {. . . . . }
$$

It may be pointed out that even if the assumption that aldehyde-vapour dissolved in acetic acid follows Henry's law is not strictly accurate, no great error will be committed, because the quantity dissolved is not large.

We also have the equation expressing the total pressure $\mathrm{P}$ 
as the sum of the pressures of oxygen $(b-x)$, aldehyde $p_{2}$, acetic-acid vapour $m$, and nitrogen $\mathrm{N}$, viz. :-

$$
\mathrm{P}=(b-x)+p_{2}+m+\mathrm{N} \text {. }
$$

Substituting the value of $p_{2}$ just found, we get

$$
\mathrm{P}=(b-x)+\frac{a-2 x}{1+k^{\prime}(x-m)}+m+\mathrm{N} \text {. }
$$

From this equation $x$ (the diminution in the oxygen pressure) may be obtained when $k^{\prime}$ is known. The analysis of the gas at the end of an experiment gives a direct determination of $x$ from which $k^{\prime}$ may be found. The expression is unfortunately a quadratic in $x$, and is best solved by successive approximations, which, however, makes the calculations somewhat laborious.

The connexion between the velocity with which oxygen and aldehyde-vapour unite to form acetic acid and the concentration of the gases (or their partial pressures, which are proportional to the concentrations) is expressed by the equation

$$
-\frac{d p_{1}}{d t}=\mathrm{K} \cdot \sqrt{p_{1}} \cdot p_{2} \cdot \cdot \cdot \cdot \cdot .
$$

$p_{1}=$ the partial pressure of the oxygen, $p_{2}$ that of the aldehyde. $-\frac{d p_{1}}{d t}$ is the rate at which the pressure of the oxygen diminishes.

To integrate this equation substitute (from equation 4)

and

$$
\begin{aligned}
& p_{2}=\frac{a-2 x}{1+k^{\prime}(x-m)}, \\
& p_{1}=(b-x),
\end{aligned}
$$

$$
-\frac{d p_{1}}{d t}=\frac{d v}{d t}
$$

This gives

$$
\frac{d x}{d t}=\mathrm{K} \cdot(b-x)^{\frac{1}{2}} \cdot\left(\frac{a-2 x}{1+k^{\prime}(x-m)}\right) .
$$

After performing the integration this becomes

$$
\begin{array}{r}
\mathrm{K} t=\frac{2 k^{\prime} m-k^{\prime} a-2}{4\left(\frac{2 b-a}{2}\right)^{\frac{2}{2}}} \log \frac{(b-x)^{\frac{1}{2}}-\left(\frac{2 b-a}{2}\right)}{(b-x)^{\frac{1}{2}}+\left(\frac{2 b-a}{2}\right)^{\frac{1}{2}}} \\
+k^{\prime}(b-x)^{\frac{1}{2}}+\text { const. }
\end{array} .
$$


The constant is obtained from the condition that $x=0$, when $t=0$.

This form of the integrated equation can only be used when $(2 b-a)$ is positive, because its square root occurs in the expression. For the case that excess of aldehyde is present at the commencement of the experiment, and $(2 b-a)$ therefore negative, the integrated equation may be brought into the following form:-

$\mathrm{K} t=\frac{2 k^{\prime} m-2-k^{\prime} a}{2\left(\frac{a-2 b}{2}\right)^{\frac{1}{2}}} \tan ^{-1} \frac{(b-x)^{\frac{1}{2}}}{\left(\frac{a-2 b}{2}\right)^{\frac{1}{2}}}+k^{\prime}(b-x)^{\frac{2}{2}}+$ const. . (5 $\left.b\right)$

The values of $\mathrm{K}$ in Table VI. are calculated by means of equations $(5 a)$ and $(5 b)$, and show that up to a pressure of 450 millim. these equations are in harmony with the experimental results.

When the partial pressure of the oxygen is higher than about 450 millim., however, the values of $\mathrm{K}$ decrease. This points to the existence of an upper limit of pressure, above which the reaction either stops altogether or goes forward with a velocity very much smaller than that which would be deduced from equation 5 .

As a matter of fact, in the two last experiments given in Table VI. no reaction occurred when the pressure of the oxygen exceeded 530 millim. Further experiments are, however, needed in order to put this very interesting behaviour beyond doubt.

We may say, therefore, that oxygen and aldehyde-vapour react with formation of acetic acid with a velocity which is proportional to the pressure of the aldehyde-vapour and to the square root of the pressure of the oxygen. It is possible that a pressure of oxygen exists above which this is no longer true. At $20^{\circ}$ this pressure appears to be that due to about 450 millim. of mercury.

INTERPRETATION OF Reisults.

Following van't Hoff*, the velocity of a reaction of the general form

$$
m \mathrm{~A}+n \mathrm{~B}+\ldots=p \mathrm{C}+q \mathrm{D}+\ldots
$$

that is of one in which $m$ molecules of a sulstance $A$ react with $n$ molecules of $\mathrm{B}$, \&c., to form $p, q$, \&c. molecules of the new substances $\mathrm{C}, \mathrm{D}, \& \mathrm{c}$, may be written

$$
-\frac{d \mathrm{C}_{1}}{d t}=k \cdot \mathrm{C}_{\mathbf{A}}^{m} \cdot \mathrm{C}_{\mathbf{B}}^{n} \ldots . . . . .
$$

* Etudes de Dynamique Chimique. 
$-\frac{d \mathrm{C}_{1}}{d t}$ is the rate at which the system $\mathrm{A}_{1} \mathrm{~B}_{1} \ldots$ changes into the other system $C_{1} D_{1} \ldots \quad C_{1}$ is the concentration of the first system, $\mathrm{C}_{\mathrm{A}}, \mathrm{C}_{\mathrm{B}}$, \&c. the concentrations of the substances $\mathrm{A}, \mathrm{B} \ldots$

In cases in which the numbers of molecules taking part in a reaction are unknown, measurements of the velocity of the reaction may be made use of for their determination.

Applying this to the reaction between aldehyde and oxygen, we have $-\frac{d \mathrm{C}_{1}}{d t}$ in equation 6 proportional to $-\frac{d p}{d t}$ in equation $5 . \mathrm{C}_{\mathrm{A}}$ we may put proportional to the pressure of the aldehyde-vapour, and $C_{B}$ to the pressure of the oxygen gas. Making these substitutions in 6, we get

$$
-\frac{d p_{1}}{d t}=\text { const. } p_{2}^{m} \cdot p_{1}^{n}
$$

and comparing this with 5 , we see that $m=1$ and $n=\frac{1}{2}$. The reaction between aldehyde and oxygen may therefore bewritten

$$
\mathrm{C}_{2} \mathrm{H}_{4} \mathrm{O}+\mathrm{O}=\mathrm{C}_{2} \mathrm{H}_{4} \mathrm{O}_{2} \text {. }
$$

We must suppose that the reaction consists in the addition of an oxygen atom to a molecule of aldehyde.

The assumption that a certain small number of oxygen atoms exist normally in oxygen gas, is in accordance with our present knowledge on the subject. Williamson was led by his studies on the formation of ethers to propose the theory that the atoms of which the molecules of a gas are composed frequently change partners. For this to be possible, a certain number of atoms must be at any moment in the act of transition, that is free. The theory of Clausius, based on the phenomena of electrolytic conductivity, and more recently that of Arrhenius, supposes a similar condition to exist in solutions of electrolytes. In 1884 J. J. Thomson * developed a mathematical theory of chemical reactions between gases, based on the ideas of Williamson and Clausius ; the results are in agreement with those obtained experimentally with aldehyde and oxygen.

The probability of the existence of free atoms in oxygen gas may be shown in another way. There can be little doubt, from analogy, that the oxygen molecule would, at a sufficiently high temperature, be dissociated into its atoms. Equilibrium will be established when the concentration of the atoms has reached a certain value which is determined by the equation

$$
\mathrm{C}_{\left(\mathrm{O}_{2}\right)}=k \mathrm{C}_{(\mathrm{O})}^{2} \text {, }
$$

where $\mathrm{C}_{\left(\mathrm{O}_{2}\right)}$ is the concentration of the oxygen molecules and

* Phil. Mag. [5] xviii. p. 233 (1884). 
$\mathrm{C}_{(0)}$ that of the atoms. $k$ is a constant which depends on the temperature*. As the heat of formation of the oxygen molecule from its atoms is probably positive, the equilibrium will change with falling temperature, in such a way that the concentration of the oxygen atoms will diminish. It will, however, probably never become nothing. If this be true at ordinary temperatures, we shall have

$$
\mathrm{C}_{(\mathrm{O})}=\text { const. } \sqrt{\mathrm{C}_{\left(\mathrm{O}_{2}\right)}} \text {. }
$$

As the concentration of the oxygen atoms is small, we can put the concentration of the oxygen molecules proportional to the pressure of the gas, and the concentration of the oxygen atoms will then be proportional to the square root of the pressure of oxygen. If we assume, therefore, that the atoms alone take part in the oxidation of the aldehyde, we shall have the velocity of the reaction always proportional to the square root of the pressure of the oxygen.

Although the rosults of the experiments with aldehyde almit of such a simple interpretation, it is doubtful whether this is also the case with those obtained with phosphorus and sulphur.

We should expect the connexion between the volocity of the reaction and the concentration of the oxygen to be less simple than that actually found.

Possibly in the case of sulphur and phosphorus with dry oxygen the reaction takes place in stages; for example,

$$
\mathrm{P}_{4}+\mathrm{O}=\mathrm{P}_{4} \mathrm{O} \dagger \text {. }
$$

The velocity of the whole reaction would then be the sum of the velocities of the part reactions, each one of which would be proportional to the concentration of the oxygen atoms. This view is also in agreement with the fact that when phosphorus is burnt with a limited supply of oxygen, the lower oxides, such as $\mathrm{P}_{4} \mathrm{O}_{6}$, are formed.

The fact that the presence of moisture accelerates the oxidation of phosphorus $\ddagger$ and sulphur is also in accordance with the view that the oxidation is due to the presence of oxygen atoms ; for Professor J. J. Thomson $\S$ has found that it is

* See van't Hoff, Etudes, p. 127.

+ The existence of this oxide, discovered by Le Verrier, is rendered probable by the work of Reinizer and Goldschmidt (Berl. Ber, xiii. p. 845, 1880 ).

In very dry oxygen phosphorus apparently does not oxidize at all. (H. B. Baker, Phil. Trans. 1888, p. 571.) Unfortunately Baker does not mention particularly the pressure under which the oxygen stood. Sulphur still burns in extremely dry oxygen, but with much greater difficulty than when the gas is moist. (Baker; and also Dewar, Proc. Roy. Soc. January 1893.)

$\S$ J. J. Thomson, British Association, Oxford Meeting, 1894. 
much more easy to cause an electric discharge (without electrodes) to pass through moist oxygen than through the gas when it is dry. The moisture apparently favours the formation of the atoms which carry the discharge. It must be confessed, however, that this view does not explain the formation of ozone which accompanies the oxidation of phosphorus, not only in moist oxygen but also, according to Marchand*, in the dry gas.

The complicated nature oi the reaction which takes place when phosphorus is oxidized in presence of water makes it impossible to do more than guess at an interpretation of the results obtained. Perhaps, however, the different nature of the equation representing the connexion between the velocity of the reaction and the pressure of the oxygen is due to the water taking part in the reaction.

The interesting fact that a pressure of oxygen exists at which the oxidation has a maximum velocity in the case of phosphorus, and perhaps also in that of aldehyde, requires further investigation before any satisfactory attempt can be made to account for it.

In conclusion it is perhaps worth noticing that, in one or two other cases which have been studied by other observers, the results are in harmony with the theory of Williamson.

Le Châtelier $\dagger$ has shown, using the results of Hautefeuille and Margottet, that, at constant temperature, the equilibrium which occurs when chlorine, hydrogen, and oxygen are exploded together can be represented by the expression

$$
\log \frac{p_{\left(\mathrm{O}_{2}\right)} \times p_{(\mathrm{HCl})}^{4}}{p_{\left(\mathrm{Cl}_{2}\right)}^{2} \times p_{\left(\mathrm{H}_{2} \mathrm{O}\right)}^{2}}=\text { const., }
$$

in which $p_{\left(\mathrm{O}_{2}\right)}, p_{(\mathrm{BCl})} \ldots$ are the partial pressures in the equilibrium of the oxygen, hydrochloric acid,....

If we suppose the reaction to occur between dissociated molecules we may write the reaction which occurs as follows:-

$$
2 \mathrm{HCl}+\mathrm{O} \rightleftarrows 2 \mathrm{Cl}+\mathrm{H}_{2} \mathrm{O}
$$

which would correspond to the equation

$$
\log \frac{p_{\left(\mathrm{O}_{2}\right)}^{\frac{1}{2}} \times p_{(\mathrm{HCl})}^{2}}{p_{\left(\mathrm{Cl}_{2}\right)} \times p_{\left(\mathrm{H}_{2} \mathrm{O}\right)}}=\frac{\text { const. }}{2}
$$

which is the equation given by Le Châtelier after dividing both sides by 2 .

In conclusion, my best thanks are due to Prof. van't Hoff, in whose laboratory the foregoing work was done, for his advice and assistance during its progress.

* Journ. prakt. Chem. 1, p. 1 (1850).

$\dagger$ Comptes Rendus, cix. p. 665 (1889). 